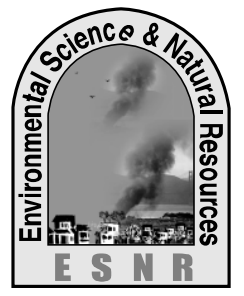

J. Environ. Sci. \& Natural Resources, 6(1): 145 - 152, 2013

ISSN 1999-7361

\title{
Crab Fattening in Bangladesh: A Socio-economic Perspective
}

\section{Z. Ferdoushi}

Department of Fisheries Management, Hajee Mohammad Danesh Science and Technology University

Dinajpur

\begin{abstract}
The study was conducted to assess the socio-economic condition of the crab fatteners in the southwest part of Bangladesh. About 52\% farmers have an experience of 5 to 10 years of indicating that involvement in mud crab fattening is the recent development and innovation in those areas. The Hindus in the coastal region found to have more interest in crab farming. On the other hand, about $27 \%$ Muslim were also found to involve in this farming. Comparatively higher involvements of Hindus farmers were found in Khulna region. Mostly young people found to have more involvement ranging from 26 to 35 years old which constituted more than $38 \%$ of the total interviewed population. About $40 \%$ farmers showed higher satisfaction by crab fattening while, few farmers reported some negative perception. Most of their farming were small scale and the farmers also accounted the higher seed cost with low profitability. However, well developed co-operation and partnership between farmers, fishermen, middlemen and wholesaler can also improve this sector for sustainable development.
\end{abstract}

Key words: Fattening, Mud crab, socio-economic condition

\section{Introduction}

Adoption of technology significantly influenced by several factors such as age, education, experience, farmer's religion, labour force size, land holdings, types of land, training, demographic characteristics of farm household, social background etc. (Paudel and Thapa, 2004). Adaptation also varies from farm to farm, village to village, community to community and even household to household in the same community (Thapa and Weber, 1990). So, it is imperative task for assessing the adaptation of a new or developed technology through examining that who are adopting improved technology or who are adopting them at a lower rate the other groups (Doss and Morris, 2001; Nederlof et al. 2004).

In the recent year analyzing livelihoods is increasingly gaining interest as a new approach for developing countries to reduce rural poverty. Impacts of aquaculture in livelihood especially in the rural areas significantly contribute the effective development for future policy and efficient technologies (Edwards, 1999). So, analyzing the livelihood frameworks with its changing patterns is essential for assessing any aquaculture (Pullin, 2001).

The growth of mud crab aquaculture is likely to lead changes to the ecological, socio-economic and livelihoods. Mangrove crab culture also has the advantage of being able to integrate within mangrove systems and therefore is often seem as a way to promote sustainable forms of aquaculture for low income-poor groups (Maung, 2006). In compare to other aquaculture, crab fattening requires less space and time with higher profitability playing an important role in income generation as a whole economy of Bangladesh. It could be a majorgenerating element in rural development programs especially in the coastal region of Bangladesh. Considering all above, the present study was undertaking to describe the socio-demographic characteristics of the mud crab fattening farmers in the southwest part of Bangladesh. The study also explores the farmer's perception towards crab fattening in the Bangladesh.

\section{Methodology}

The study was undertaken in the Southwest part of Bangladesh. Khulna and Bagherhat two districts were selected for this study as most of the crab fattening farms are located in this region and it is near to Sundarbon mangrove region which is the main source of crab fry for this culture. A total of 100 households were selected for the purpose of this study.

Socio-demographic characteristics were measured by using a semi-structure questionnaire during the period of study. Data were collected from the crab fattening farmers using questionnaire interviews, Participatory Rural Appraisal (PRA) tools such as Focus Group Discussion (FGD) and Cross-check interview with key informants. Age of a respondent was measured in terms of actual years on the basis of his statement. A score of 1 was assigned for each years of age. For measuring education, a respondent who could not reads and write falls under illiteracy criteria with a score of 0,1 score was given who had primary education, for secondary categories as 2, having secondary school certificate categories as 3 and having more than secondary education categories as 4. Moreover for measuring the schooling period, a score of 1 was assigned to a responded for each year of school. Respondent who received training categories as 1 and who did not categories on the score 0 . Years of experience also measured as years of 
farming they involved. Finally data were processed and analyzed using tabular method.

\section{Results and Discussion}

Table 1 is showing the socio-demographic characteristics of the involved farmers in mud crab (Scylla sp.) fattening. Compare to other region the Hindu population is three times higher in coastal region of Bangladesh. Hannan (1994) also reported that the higher number of fisherman in coastal area of Bangladesh came from low cast of Hindu society. However, Mud crab farming in Bangladesh is quite new. The Hindu people in the coastal region found to have more interest in crab farming $(73 \%)$. On the other hand, about $27 \%$ Muslim were also found to involve in this farming. Comparatively higher involvements of Hindus farmers were found in Khulna region $(80 \%)$ followed by Bagerhat $(66 \%)$ (Table 1).

The nation's key socio-economic issues are affected by the age structure. For estimating the potential human resources knowledge of the age structure of farmers is important.

Table 1: Demographic profiles of mud crab fatteners in the study areas.

\begin{tabular}{|c|c|c|c|}
\hline Religion & $\begin{array}{c}\begin{array}{c}\text { Khulna } \\
\mathbf{n}=\mathbf{5 0}\end{array} \\
\end{array}$ & $\begin{array}{c}\text { Bagerhat } \\
\mathbf{n}=50\end{array}$ & $\begin{array}{c}\text { Total } \\
\mathbf{N}=100\end{array}$ \\
\hline Muslim & $10(20)$ & $17(34)$ & $27(27)$ \\
\hline Hindus & $40(80)$ & $33(66)$ & $73(73)$ \\
\hline \multicolumn{4}{|l|}{ Age distribution } \\
\hline Up to 25 years & $12(24)$ & $8(16)$ & $20(20)$ \\
\hline 26 to 35 years & $21(42)$ & $17(34)$ & $38(38)$ \\
\hline 36 years to 45 years & $12(24)$ & $20(40)$ & $32(32)$ \\
\hline More than 45 years & $5(10)$ & $5(10)$ & $10(10)$ \\
\hline \multicolumn{4}{|l|}{ Educational level } \\
\hline No academic education & $11(22)$ & $7(14)$ & $18(18)$ \\
\hline Up to primary level & $20(40)$ & $9(18)$ & $29(29)$ \\
\hline Up to secondary level & $11(22)$ & $18(36)$ & $29(29)$ \\
\hline Up to SSC & $7(14)$ & $12(24)$ & $19(19)$ \\
\hline More than SSC & $1(2)$ & $4(8)$ & $5(5)$ \\
\hline \multicolumn{4}{|l|}{ Number of Household } \\
\hline Up to 4 person & $13(26)$ & $12(24)$ & $25(25)$ \\
\hline 5 to 6 person & $20(40)$ & $16(32)$ & $36(36)$ \\
\hline 7 to 8 person & $14(28)$ & $10(20)$ & $24(24)$ \\
\hline More than 8 person & $3(6)$ & $12(24)$ & $15(15)$ \\
\hline \multicolumn{4}{|l|}{ Occupation } \\
\hline $\begin{array}{lll}\text { Crab fattening as main } \\
\text { occupation }\end{array}$ & $35(70)$ & $28(56)$ & $63(63)$ \\
\hline Agriculture & $15(30)$ & $22(44)$ & 37 (37) \\
\hline \multicolumn{4}{|l|}{ Total land area (decimal) } \\
\hline Average & $167.02 \pm 259.17$ & $187.21 \pm 223.96$ & $177.11 \pm 241.19$ \\
\hline Maximum & 1500 & 1055 & 1500 \\
\hline Minimum & 20 & 6.8 & 6.8 \\
\hline \multicolumn{4}{|l|}{ Annual income (US\$/year) } \\
\hline Average & $1360.70 \pm 669.21$ & $1366.26 \pm 602.30$ & $1363.48 \pm 633.42$ \\
\hline Maximum & 3130.44 & 3478.26 & 3478.26 \\
\hline Minimum & 660.87 & 869.57 & 660.87 \\
\hline
\end{tabular}




\section{Data in the parenthesis is showing the percentage}

It has significant influence on the planning education, health and employment. In the present study, from the age distribution results it was observed that a wide range of different age of people was involved in fattening of crabs. Mostly young people found to have more involvement ranging from 26 to 35 years old which constituted more than $38 \%$ of the total interviewed population.

Human resource largely depends on the literacy and educational attainment. Farmer's literacy and educational status has significant influence on technical skillness and that might also have positive effects on income generation, expenditure and saving activities. In the present study the educational status was found better in Bagerhat region compared to the Khulna. An average, $18 \%$ farmers did not have any formal education. Among them, higher proportion was observed in Khulna followed by Bagerhat. Very few farmers had (only 5\%) more than secondary school certificate education.

Among different human capitals, family size or number of household in an important one. About 36\% of the total farmers interviewed in the study areas having the household size within 5 to 6 people. It is directly linked with the employment, occupation and income (Ignacy, 1994). According to Gill and Motahar (1982) it could be a constraint factor for the farm productivity or efficiency. Larger family may make it difficult to invest in farming due to financial constrains.

Main occupation is that to which more than half of the total working hours are devoted, while secondary occupation is defined to which less than half of the total working time is devoted (Hartog and Van Staveren, 1983). The occupation of the respondents were divided broadly into two categories; primary and secondary occupation. Crab farming was considered as primary occupation, while farmers having other profession such as other agriculture as major income source, for them crab farming was considered as secondary occupation. In the study areas, several types of occupations were observed among the farmers. Two types of occupations were considered for the current survey. One is crab farming; another one is other agricultural activities besides crab farming. However, from the survey results it revealed that for $63 \%$ interviewed farmers took crab fattening as their main occupation. The rest $37 \%$ farmers it was secondary occupation. Besides other agriculture, such as paddy cultivation they took crab farming as secondary income source. Significant difference also observed among the farmers regarding their occupation at $1 \%$ level of significance. Only 56\% farmers in Bagerhat took crab fattening as main occupation while more than $70 \%$ farmers in Khulna.

Land holdings are important requirement playing significant role in the socio-economic status for rural as well as peri-urban people of Bangladesh (Khan, 2004). Total land size was measured by adding the total homesteads area, own cultivated area, pond and garden. Average land area was about 177.11 \pm 241.19 decimal. It is evident from the Table 1 that the average land area in Bagerhat region was higher by Khulna. Between two areas, farmers in Bagerhat region found to have higher average land holdings compared to Khulna. Their average annual income in Bagerhat region $\left(1366.26 \pm 602.30\right.$ US\$ year $\left.{ }^{-1}\right)$ was also found slightly higher than Khulna region

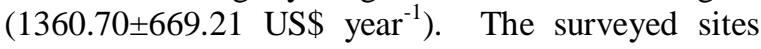
from Bagerhat region are situated in the port site and found to have more income generating activities compare to other two regions. In addition to this, surveyed sites in Khulna region are more vulnerable to the cyclones and other natural disaster. That might be the cause for small land holding capacity and poor economic condition of the Khulna and Satkhira districts' farmers compare to Bagerhat district.

Housing condition is an indicator of wealth. The types of the house were observed in the study area are mud thatched (wall and roof mainly made by mud and thatched), tin shed with mud made wall, half building made by brick and tin shaded roof and full building (the wall and roof made by brick and concrete). Most of the houses in the studied areas were tin shaded while only $7 \%$ farmers were lived in full building houses. Average house size in Bagerhat region found higher than Khulna region. Average house size was about $347.05 \pm 119.68 \mathrm{~m}^{2}$ ranging from $121.46 \mathrm{~m}^{2}$ to $728.74 \mathrm{~m}^{2}$ (Table 2).

Among different social facilities, about $70 \%$ farmers in Bagerhat found to have electricity facility followed by $58 \%$ in Khulna. Almost half of the interviewed farmers in the surveyed areas had no electricity facility. The sanitary condition in the rural area of Bangladesh is very poor especially the poor people in the coastal region are in worst condition. Two types of toilet are found in the survey areas. One is Kacha toilet-made of bamboo with leaf shelter and inadequate drainage disposal and another one Pucca toilet made of brick with food drainage disposal. Only 73\% farmers were found to have Pucca sanitary facility. Farmers in Bagerhat region were found in better condition regarding having good sanitary facility compared to Khulna. About $34 \%$ farmers in Khulna found to have Kacha sanitary facility. 
Table 2: Social condition of mud crab fatteners in the study areas.

\begin{tabular}{|c|c|c|c|}
\hline Housing condition/type & $\begin{array}{c}\begin{array}{c}\text { Khulna } \\
\mathrm{n}=50\end{array} \\
\end{array}$ & $\begin{array}{c}\text { Bagerhat } \\
\mathbf{n}=50\end{array}$ & $\begin{array}{c}\text { Total } \\
\mathrm{N}=100\end{array}$ \\
\hline Mud thatched & $11(22)$ & $17(34)$ & $28(28)$ \\
\hline Tin shaded & $23(46)$ & $24(48)$ & $47(47)$ \\
\hline Half building & $12(24)$ & $6(12)$ & $18(18)$ \\
\hline Full building & $4(8)$ & $3(6)$ & $7(7)$ \\
\hline \multicolumn{4}{|l|}{$\begin{array}{l}\text { House size } \\
\left(\mathrm{m}^{2}\right)\end{array}$} \\
\hline Average & $343.32 \pm 102.89$ & $350.77 \pm 135.37$ & $347.05 \pm 119.68$ \\
\hline Maximum & 526.32 & 728.74 & 728.74 \\
\hline Minimum & 121.46 & 121.46 & 121.46 \\
\hline \multicolumn{4}{|l|}{$\begin{array}{l}\text { Electricity } \\
\text { facility }\end{array}$} \\
\hline No & $21(42)$ & $15(30)$ & $36(36)$ \\
\hline Yes & $29(58)$ & $35(70)$ & $64(64)$ \\
\hline \multicolumn{4}{|l|}{ Sanitary facility } \\
\hline Pucca & $33(66)$ & $40(80)$ & $73(70)$ \\
\hline Kacha & $17(34)$ & $10(20)$ & $27(27)$ \\
\hline \multicolumn{4}{|l|}{ Road facility } \\
\hline Only road & $24(48)$ & $37(74)$ & $61(61)$ \\
\hline Only water & $3(6)$ & $0(0)$ & $3(3)$ \\
\hline Both & $23(46)$ & $13(26)$ & $36(36)$ \\
\hline \multicolumn{4}{|l|}{ Source of drinking water } \\
\hline Tube-well water & $30(60)$ & $37(74)$ & $67(67)$ \\
\hline Pond water & $20(40)$ & $13(26)$ & $33(33)$ \\
\hline \multicolumn{4}{|l|}{ Health service } \\
\hline MBBS doctors & $3(6)$ & $4(8)$ & $7(7)$ \\
\hline Upazila Health Complex & $18(36)$ & $18(36)$ & $36(36)$ \\
\hline Village doctors & $29(58)$ & $28(56)$ & $57(57)$ \\
\hline \multicolumn{4}{|l|}{ Availability of Television } \\
\hline No & $22(44)$ & $16(32)$ & $38(38)$ \\
\hline Yes & $28(56)$ & $34(68)$ & $62(62)$ \\
\hline
\end{tabular}

\section{Data in the parenthesis is showing the percentage}

Among different social facilities, about $70 \%$ farmers in Bagerhat found to have electricity facility followed by $58 \%$ in Khulna. Almost half of the interviewed farmers in the surveyed areas had no electricity facility. The sanitary condition in the rural area of Bangladesh is very poor especially the poor people in the coastal region are in worst condition. Two types of toilet are found in the survey areas. One is Kacha toilet-made of bamboo with leaf shelter and inadequate drainage disposal and another one Pucca toilet made of brick with food drainage disposal. Only $73 \%$ farmers were found to have Pucca sanitary facility. Farmers in Bagerhat region were found in better condition regarding having good sanitary facility compared to Khulna. About 34\% farmers in Khulna found to have Kacha sanitary facility.
About 36\% farmers had the road and waterway as a means of transport, while $6 \%$ farmers in Khulna only had the water way. Farmers from Khulna distrcit having more access $(46 \%)$ to road and water compared to Bagerhat.

Safe and clean drinking water is the most valued elements in society (Tellegen et al. 1996). In Bangladesh, the water supplies are based on collecting rainwater, ponds pit walls, shallow and deep tube-well. In the present survey farmers mainly collecting their drinking water from pond or from tube-well (Table 2).

During the survey period, the interviewed farmers were requested to state the type of health services that they could afford for him and his family. Only $7 \%$ of them reported to go to MBBS doctors. Among them 
highest percentage was observed in Bagerhat region followed by Khulna While more than $57 \%$ farmers were dependent on village doctors who are generally unqualified practitioners with improper knowledge of medical science. On the other hand, around 36\% of them stated that they usually go to the UHC (Upazila
Health Complex).

Figure 1 showing farmers distribution of two areas according to experience, ownership of the pond, source of credit for farming, sources of loan available to them for crab farming.

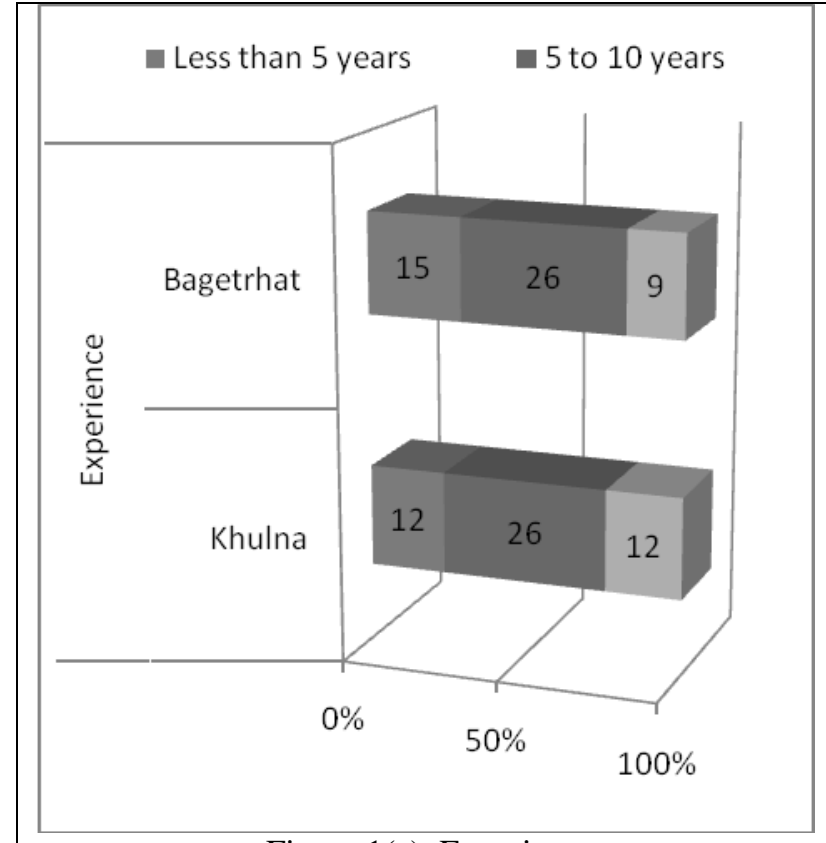

Figure 1(a) Experience

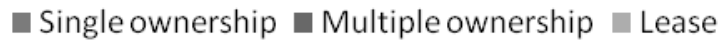

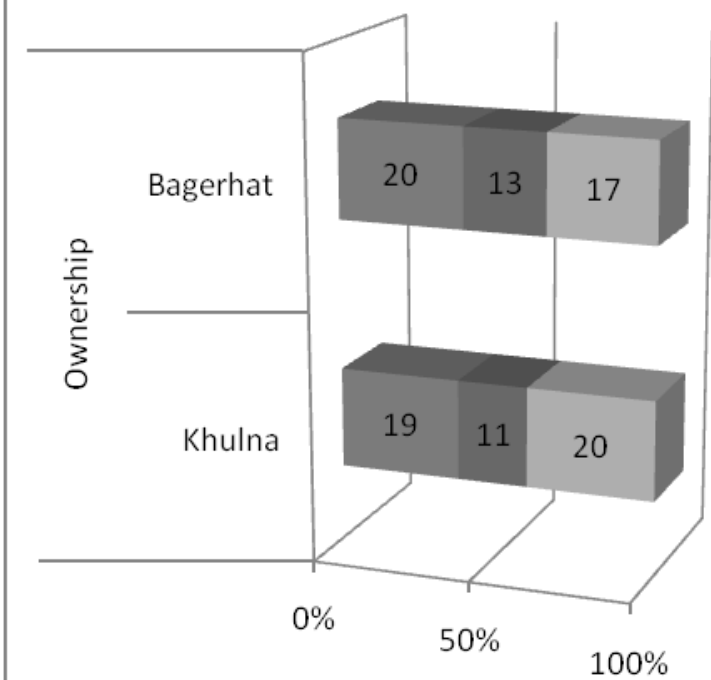

Figure 1(b) Ownership

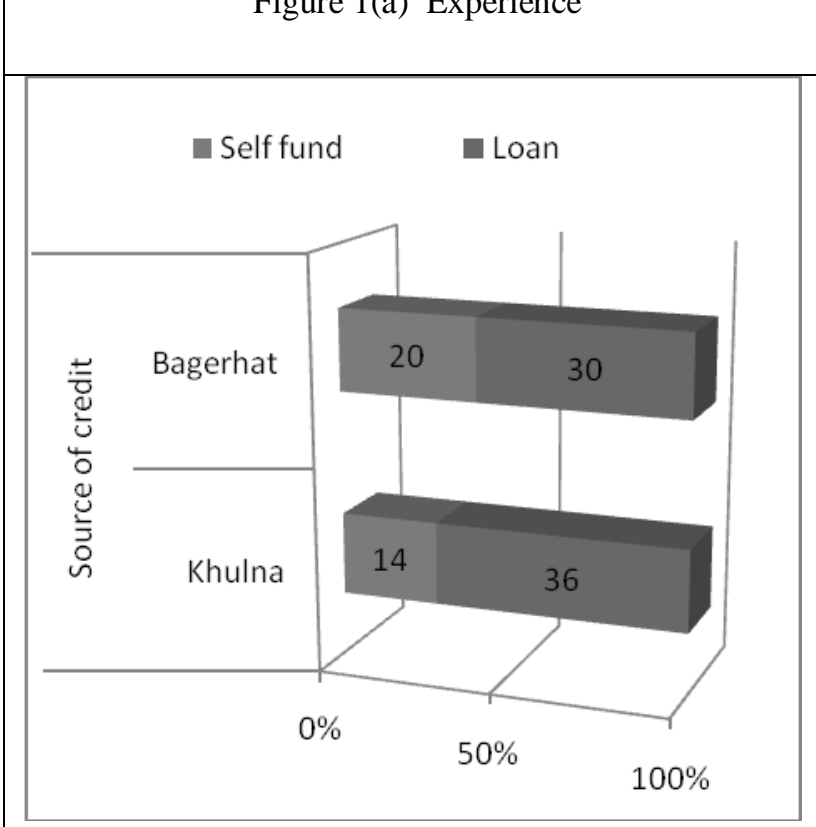

Figure 1(c) Source of credit

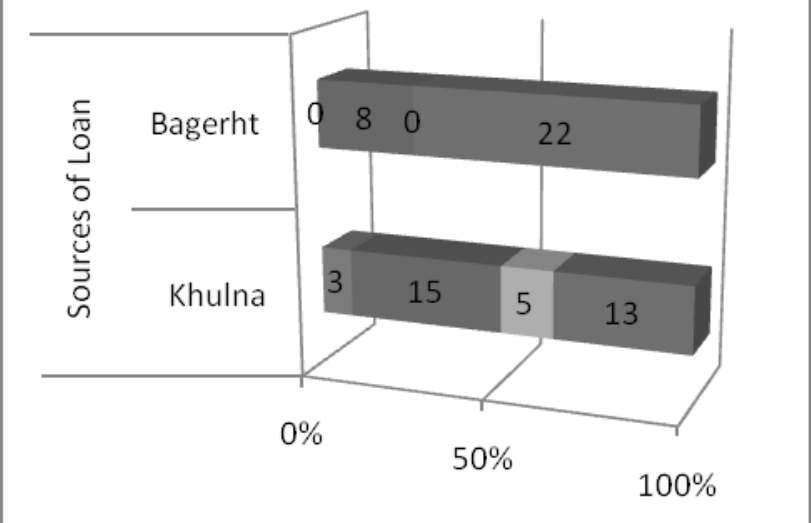

Figure 1(d) Source of loan

Fig 1: Farmers distribution of different parameters related to mud crab fattening (experience, ownership of the pond, source of credit and sources of loan for crab fattening). 
A total of $52 \%$ farmers found to have 5 to 10 years of experience (Figure 1a). About 24\% farmers in Khulna found to have more than 10 years experience in crab fattening followed by Bagerhat (18\%). However, the year of experience indicating that involvement in mud crab fattening is the recent development and innovation in those areas.

Ownership of the land is also a crucial determinant of the incentive for investing money, of the ability to obtain credit and ultimately encouraging the overall household income. Secure and self owned land might influence the proper management and rights in all aspects. For this study, pond ownership categories into three groups based on access i.e. self owned, multiple share, and lease. The term share refers to pond which is owned by more than one household, lease refers to the arrangement whereby the pond owner made a contact with the user for a certain period of time. However, most of the ponds in the present survey belongs to category ownership (39\%). On the other hand, about $37 \%$ and $24 \%$ of the ponds were either leased or under a multiple ownership arrangement (Figure 1b).

Farmers in the survey areas were also asked about their source of fund for farming crabs. About $66 \%$ of the farmers found to take loan for this farming. Highest percentage was observed in Khulna region (72\%) followed by Bagerhat region (60\%). They found to take this loan from Banks, NGOs, depot or from local moneylenders. However, in the survey areas, most of the farmers took loan from depot with a contact to sell their harvested crab to that depot owner.

Loan facility from government bank for crab farming was not reported in the survey areas. Farmers usually found to take loan from different NGOs, from depot, local money lenders or from other commercial non government or private bank. However, among 66 farmers who took loan were also asked about the source of loan. Only 3\% farmers were found to take loan from Bank followed by $5 \%$ farmers who took from money lender. While $35 \%$ farmers found to take loan from different local NGOs.

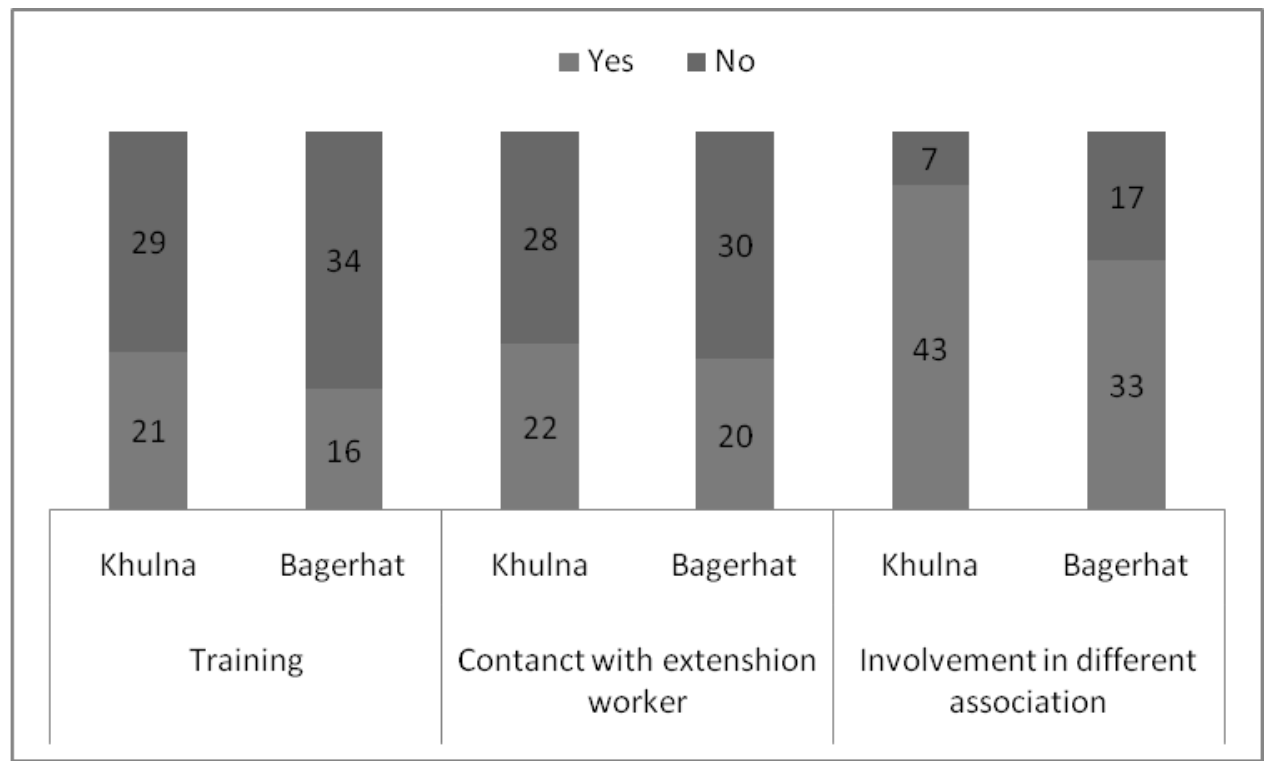

Fig 2: Farmers distribution of different parameters (Training, contact with extension workers, and involvement of different associations)

It was revealed from the survey that more than $63 \%$ farmers in the surveyed area did not get any training related to crab farming (Figure 2). According to their statements, neibours and friends who received training are their main source of learning this farming. During the survey, it was reported that only half of the interviewed farmers had close contact with the extension workers. Farmers in Khulna had more contact followed by Bagerhat (40\%) district.
During the survey, some farmers were also found to involve in different societies, such as fish farmers association or other different multipurpose cooperative society. About $76 \%$ of them found to involve in any association while only $24 \%$ farmers were not involve in any association. The farmers in Khulna (86\%) were found to be more attached with different association (Figure 2)

In the present survey areas, mainly two types of farmers associations were observed. One is 
multipurpose cooperative society formed by people come from different professions, and NGOs; another one is fish farmer association. Their activities found to be limited. The multipurpose associations are mainly covering the credit supply. While the fish farmer association mainly involved in marketing, processing and transportation of the crabs. However, most of the farmers were associated with different multipurpose associations due to credit supply. On the other hand, farmers in Khulna region were found to be more organized with the fish farmers association and getting more benefit.

During the survey, farmers were asked about their satisfaction towards the benefit from crab fattening. According to their statements, higher satisfaction were achieved in Khulna distrcis $(62 \%)$ followed by Bagerhat (18\%). Farmers in Bagerhat region reported less satisfaction in crab fattening. Moreover, $40 \%$ of them said that they are not fully satisfied with the production and profit from mud crab fattening (Figure 3 ). Most of their farming were small scale and the farmers also accounted the higher seed cost with low profitability. They were still struggling with learning curve and finding most difficulty to cover the cost. On the other hand, only $4 \%$ farmers in Khulna region reported less satisfaction than other occupation.

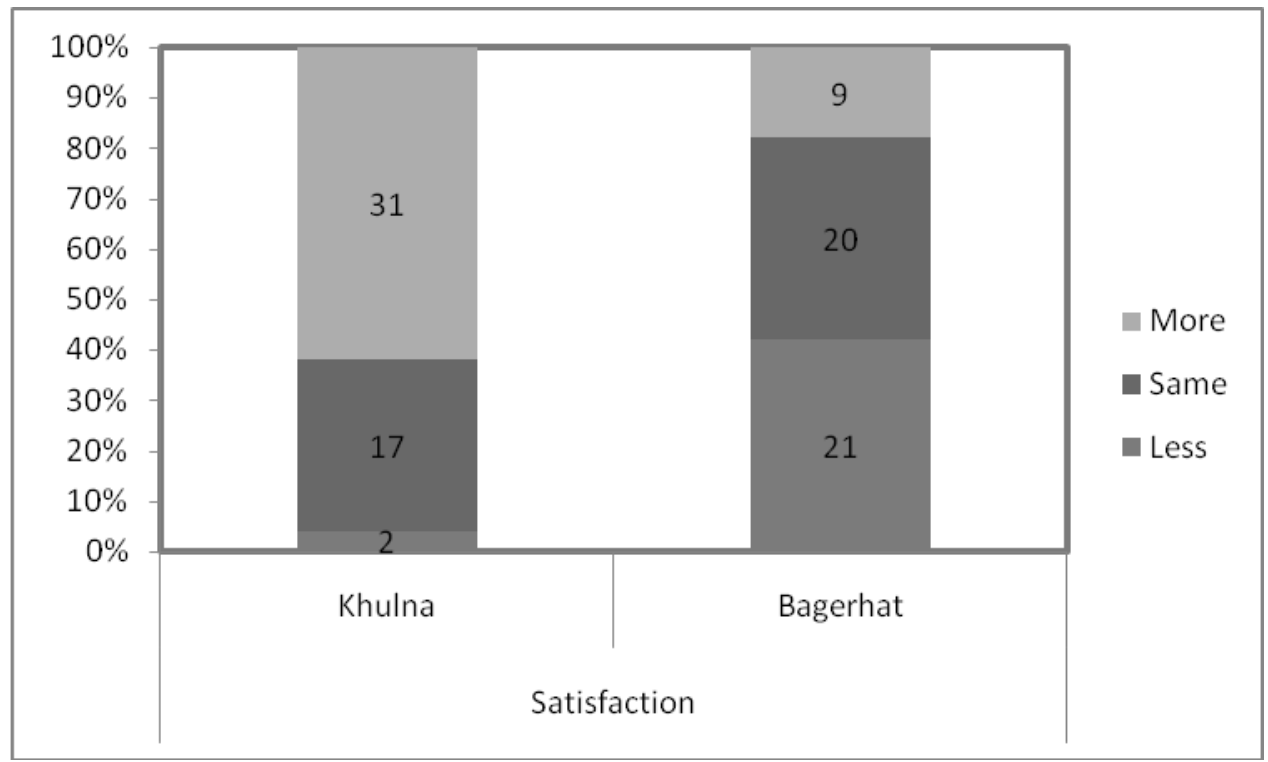

Fig 3: Farmers perception towards satisfaction for mud crab fattening according to area A story from Paikgachha, Khulna

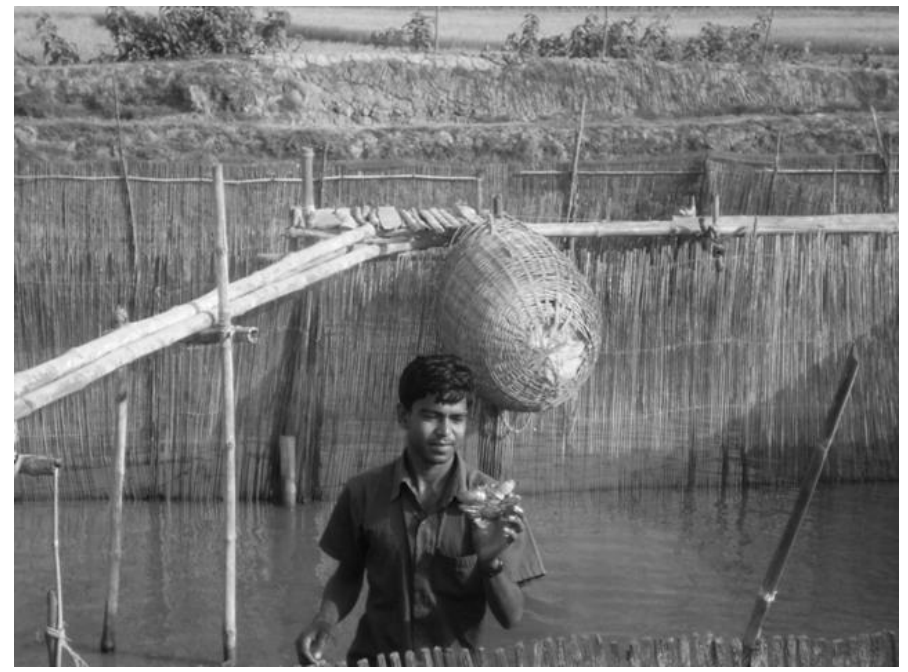

Ovimanno Kumar Mondol, age 28, mud crab fattening farmer in Paikgachha, Khulna. At first, he started his job in a crab exporting depot in Dhaka. Before he worked as a processing worker in that 
depot. During that time, he got information from depot about crab farming and observed the benefit from farming and trading. After five years, he came back to his village Paikgachha, Khulna. At first, he attended a training programme about crab farming organized by the Brackish water Fisheries Research Institute, Paikgachha, Khulna. Though he got some knowledge from the research institute, due to insufficient credit for crab farming he took loan from a local NGO called Asha. He started his farming with a leased pond (total area around 20 decimal). According to his reports, after starting crab farming his livelihood changed abruptly. He assisted his parents to arrange his sister's marriage. Now his family has enough food, clothes and passing better life than before. Beside the profits, he also reported some problems in crab farming such as, unavailability of seed and high feed cost during dry time that could be a major problem in crab farming in near future.

\section{Acknowledgement}

The author acknowledge with thanks to Chinese Government for supporting this study. The author would also like to express her gratefulness to all mud crab fatteners and the associate groups in the southwest part of Bangladesh those have given a lot of valuable information without which the study could not have been completed.

\section{References}

Doss, C. R. and Morris, M. L. 2001. How does gender affect the adoption of agricultural innovations? The case of improved maize technology in Ghana. Agriculture Economics, 25:27-39.

Edwards, P. 1999. Aquaculture and poverty: Past, Present and Future projections of impact. A Discussion Paper prepared for the Fifth Fisheries Development Donor Consultation, Rome, Italy.

Gill, G. L. and Motahar, S. A. 1982. Social factors affecting prospects for intensifies fish farming in Bangladesh. Bangladesh Journal of Agricultural Economics, 5:1-24.
Hartog, A. P. and Van Staveren, W. A. 1983. Manual for social survey on food habits and consumption in developing countries. PUDOC: Wageningen. 114p.

Hannan, M. 1994. Fisherfolk organization in Bangladesh. In: Socio-economic Issues in Coastal Fisheries Management, Proceedings of the Indo-Pacific Fishery Commission (IPFC) Symposium, 8: pp. 216-222, RAPA Publication, Bangkok, Thailand.

Ignacy, S. 1994. Population, development and employment. International Social Science Journal, 46: 343-359.

Khan, M. H. 2004. Power, Property Rights and Issue of Land Reform: A General Case Illustrated with Reference to Bangladesh. Journal of Agrarian Change, 4: 73-106.

Maung Soe K. 2006. The current of mariculture in Myanmar and livelihood opportunities for coastal communities. The future of mariculture: A regional approach for responsible development of marine farming in the Asia-Pacific Region. Bangkok: STREAM.

Nederlof, E. S., Tossou, R., Sakyi-Dawson, O. and Kossou, D. K. 2004. Grounding agricultural research in resource-poor farmers' needs: a comparative analysis of diagnostic studies in Ghana and Benin. NJAS, Wageningen, Journal of Life Science, 52: 421-442.

Paudel, G. S. and Thapa, G. B. 2004. Impact of social, Institutional and ecological factors on land management practices in mountain watersheds of Nepal. 24: 35-55.

Pullin, R. 2001. Integrated agriculture-aquaculture and the environment. In: FAO/IIRR/WorldFish Centre, (ed). Integrated agriculture-aquaculture. A primer, FAO Fisheries Technical Paper T407. FAO. Rome, Italy, pp 149.

Thapa, G. B. and Weber, K.E. 1990. Actors and factors of deforestation in Tropical Asia Environmental Conservation 17:19-27. 